From "MEC '08 Measuring Success in Upper Limb Prosthetics," Proceedings of the 2008 MyoElectric Controls/Powered Prosthetics Symposium, held in Fredericton, New Brunswick, Canada, August 13-15, 2008.

\title{
PHANTOM LIMB DEVELOPMENT IN CONGENITALLY UPPER LIMB-DEFICIENT INDIVIDUALS
}

\author{
Kristin A. Farry, Ph.D. \\ Excalibur Technical Services Incorporated
}

\begin{abstract}
We collected myoelectric data from five congenitally below-elbow limb-deficient volunteers for evaluation of a myoelectric prosthesis control system using contralateral stimulation. The volunteers reported no phantom limb experiences before the data collection, but began to feel phantom-like sensations of their missing hands during the data collection. Some described limits on their new perceptions remarkably similar to the phantom motion limits described by traumatic amputees (i.e., difficulty in fully opening and closing the phantom's fingers). Significant changes occurred in the volunteers' myoelectric data signatures after they began to feel the phantoms.
\end{abstract}

\section{INTRODUCTION}

We collected a large set of myoelectric signals from 10 upper-limb, below-elbow amputee volunteers while they each generated approximately 1000 candidate prosthesis control commands covering 6 motions. Five volunteers were traumatic amputees and five were congenitally limb deficient. Our goal was a large dataset to evaluate myoelectric control concepts, not studying phantom limbs, but we encouraged those volunteers who had a phantom sensation to use it during the data collection [1].

All five traumatic limb-deficient volunteers reported feeling a phantom limb with varying degrees of mobility prior to the data collection sessions. Three of the five traumatic amputee volunteers reported difficulty in completely opening and closing their phantom fingers. One described some difficulty in feeling their wrist. The traumatic amputee volunteers generated the command-specific contraction in their residual limb easily by moving their phantom limb simultaneously in a mirror image of their sound hand's motion. In spite of these apparent limitations, merely attempting to move the phantom limb in unison with the sound limb was sufficient for the traumatic amputees to generate consistent myoelectric signatures from which motions could be distinguished and classified [2].

\begin{tabular}{|c|c|c|c|c|l|}
\hline \multicolumn{6}{|c|}{ Table 1: Five volunteers with congenital upper limb below elbow limb deficiencies participated in this study. } \\
\hline $\begin{array}{c}\text { Subject } \\
\text { ID }\end{array}$ & Sex & Age & $\begin{array}{l}\text { Residual } \\
\text { Side }\end{array}$ & $\begin{array}{l}\text { Residual } \\
\text { Length }\end{array}$ & Comments \\
\hline 6 & Female & 32 & Right & $6.0 \mathrm{~cm}$ & $\begin{array}{l}\text { Regular body-powered hook user since early } \\
\text { childhood. Occasional myoelectric hand use. }\end{array}$ \\
\hline 7 & Male & 12 & Left & $18.4 \mathrm{~cm}$ & $\begin{array}{l}\text { No prosthesis use since age 6. Cannot fully } \\
\text { straighten elbow of residual limb. Some carpal } \\
\text { bones present. Residual forearm radius and ulna } \\
\text { fused in pronated position. Sound and residual side } \\
\text { humerus bones not equal in length. }\end{array}$ \\
\hline 8 & Female & 12 & Right & $7.0 \mathrm{~cm}$ & $\begin{array}{l}\text { Moderate myoelectric user, hand only. Mother's } \\
\text { ultrasound at 14-16 weeks of pregnancy showed two } \\
\text { hands developing normally. }\end{array}$ \\
\hline 9 & Male & 13 & Right & $9.6 \mathrm{~cm}$ & Moderate myoelectric user, hand only. \\
\hline 10 & Male & 12 & Left & $10.4 \mathrm{~cm}$ & Occasional myoelectric user, hand only. \\
\hline
\end{tabular}


From "MEC '08 Measuring Success in Upper Limb Prosthetics," Proceedings of the 2008 MyoElectric Controls/Powered Prosthetics Symposium, held in Fredericton, New Brunswick, Canada, August 13-15, 2008.

Four of the five congenitally limb-deficient volunteers (Table 1) had no phantom sensations at all prior to the data collection sessions (Table 2). The fifth volunteer occasionally felt an itch beyond the end of his residual limb, but did not feel anything like a hand. This matched the conventional wisdom that congenitally limb-deficient people never develop a map of the missing limb in their brains. We expected the congenitally limb-deficient volunteers to develop some conscious mnemonics to generate consistent motion-specific myoelectric signatures, if they could do so at all. We were not optimistic that they could develop distinct signatures for six motions. During the data collection sessions for the congenitally limb-deficient volunteers, however, these volunteers began to feel phantom limb sensations remarkably similar to those reported by our traumatic amputee volunteers.

\section{METHODS}

We captured a minimum of four channels of myoelectric data from each limb (both sound and residual limbs) from each volunteer [1]. Electrode sites were based on a quick qualitative assessment of signal strength and variation as the subject attempted some trial motions. During the data collection, the subject sat in front of a PC display monitor on which a drawing of the desired motion (open grasp, close grasp, flex wrist, extend wrist, pronate forearm, or supinate forearm) appeared in random order. The subjects imitated the pictured motion with their sound hand and simultaneously generated the command-specific contraction they had chosen for that motion in their residual limb. We use the term "contra-lateral stimulation" to describe this exercise where the user moves the intact hand and wrist while simultaneously attempting to do exactly the same action with the amputated limb. We recorded at least 150 trials of each motion type per subject. The subject had a brief rest between motion cues, which were given when the subject said they were ready for the next cue. Longer rest breaks and one meal break were given as the subject requested. Total testing time for each subject was only 3 hours.

Prior to our data collection sessions with the congenitally limb-deficient volunteers, we asked our subjects to develop a prosthesis command set (consisting of motion-specific contractions) that they could remember and associate with the proposed prosthesis movements when they saw the motion prompts. All chose to imagine moving a hand on their limb-deficient side through the desired prosthesis motions. We did not discuss the subject's choice of mental imagery until the completion of their data collection session. We discussed perception of a hand on the limb deficient side during the data collection session with only one subject (8), when that subject initiated the discussion.

We recorded the myoelectric signals at 2400 samples per second per channel, using a Fetrode electrode artifact reduction system (UFI, Morro Bay, California) consisting of disposable recessed silver-silver chloride electrodes, an amplifier and a signal conditioner. The Fetrode system has very high input impedance and virtually eliminates induced motion artifact. The recessed, wet electrodes have low motion artifacts relative to those commonly used in prostheses.

\section{RESULTS}

After our subjects told us they began "feeling" a limb partway through the data sessions, we looked for the signature of the phantom limb in the myoelectric data and prosthesis controller simulation performance. We used the subject's comments about when they became aware of the phantom limb plus motion start settling and signal-to-noise ratios to estimate the point at which the "post-phantom” data set began. Three subjects $(8,9$, and 10$)$ could name a specific time that 
From "MEC '08 Measuring Success in Upper Limb Prosthetics," Proceedings of the 2008 MyoElectric Controls/Powered Prosthetics Symposium, held in Fredericton, New Brunswick, Canada, August 13-15, 2008.

they first felt the phantom-just after an hour's lunch break. The other two (6 and 7) did not pinpoint a specific time, but mentioned an increasing awareness of a sense of having two hands. Subject 6's lunch break came relatively late in the data session. The break and its timing seem to be important in the phantom development.

\begin{tabular}{|c|c|c|c|}
\hline \multirow{2}{*}{$\begin{array}{l}\text { Sub- } \\
\text { ject }\end{array}$} & \multicolumn{3}{|c|}{ Phantom perception } \\
\hline & Prior & During & After \\
\hline 6 & None & $\begin{array}{l}\text { Began by visualizing that she had a hand } \\
\text { on her (very short) residual limb and } \\
\text { trying to move it in conjunction with her } \\
\text { sound hand; could not pinpoint a sudden } \\
\text { change or specific onset of phantom } \\
\text { sensation. Lunch break occurred just } \\
\text { before trial 500. }\end{array}$ & $\begin{array}{l}\text { "After a while, I really got into the feeling that I } \\
\text { had two hands." No follow-up was possible. }\end{array}$ \\
\hline 7 & None & $\begin{array}{l}\text { Began by visualizing that he had a hand } \\
\text { on his (very long, with some carpal } \\
\text { bones) residual limb and trying to move it } \\
\text { in conjunction with his sound hand; could } \\
\text { not pinpoint a sudden change or specific } \\
\text { onset of phantom sensation. Lunch break } \\
\text { occurred just after trial } 400 \text {. }\end{array}$ & $\begin{array}{l}\text { Reported a gradually increasing awareness of } \\
\text { his residual "forearm muscles pulling at his } \\
\text { wrist in a way that made sense." Months later, } \\
\text { he could reawaken the sensation by briefly } \\
\text { attempting contra-lateral motion. }\end{array}$ \\
\hline 8 & None & $\begin{array}{l}\text { Began by visualizing that she had a hand } \\
\text { on her residual limb and trying to move it } \\
\text { in conjunction with her sound hand; } \\
\text { began spontaneously talking about the } \\
\text { phantom sensation just after her lunch } \\
\text { break. Lunch break occurred just before } \\
\text { trial 300. }\end{array}$ & $\begin{array}{l}\text { Reported a distinct change in sensation in her } \\
\text { residual limb between the before-lunch trials } \\
\text { and the after-lunch trials. Reported difficulty in } \\
\text { completely closing and opening the fingers of } \\
\text { the phantom hand. No follow-up was possible. }\end{array}$ \\
\hline 9 & None & $\begin{array}{l}\text { Began by visualizing that he had a hand } \\
\text { on his residual limb and trying to move it } \\
\text { in conjunction with his sound hand; } \\
\text { reported a distinct change in what he felt } \\
\text { on his residual side about } 10 \text { trials after } \\
\text { his lunch break. Lunch break occurred } \\
\text { just after trial } 250 \text {. }\end{array}$ & $\begin{array}{l}\text { Reported that the sensation came to him as he } \\
\text { tried to visualize "a hand opening and closing } \\
\text { and moving" just after the lunch break. While } \\
\text { the sensation felt like much more than simply } \\
\text { the visualization he started with, "it didn't really } \\
\text { feel like part of me." Even though he did not } \\
\text { feel particularly connected to this hand } \\
\text { sensation, he noticed that he couldn't quite } \\
\text { straighten the fingers on it. Months later, he } \\
\text { could reawaken the sensation by briefly } \\
\text { attempting contra-lateral motion. }\end{array}$ \\
\hline 10 & $\begin{array}{l}\text { An } \\
\text { occasional } \\
\text { "itch" } \\
\text { located } \\
\text { beyond } \\
\text { the end of } \\
\text { residual } \\
\text { limb }\end{array}$ & $\begin{array}{l}\text { Began by visualizing that he had a hand } \\
\text { on his residual limb and trying to move it } \\
\text { in conjunction with his sound hand; } \\
\text { reported feeling like he had a wrist and } \\
\text { hand on his residual side just after his } \\
\text { lunch break and relying on it to generate } \\
\text { contractions instead of the visualization. } \\
\text { Lunch break occurred just after trial } 399 .\end{array}$ & $\begin{array}{l}\text { He noticed no limitations on the motion of the } \\
\text { hand sensation, although its response seemed a } \\
\text { little slower than that of his intact hand. Months } \\
\text { later, he could reawaken the sensation by } \\
\text { briefly attempting contra-lateral motion. }\end{array}$ \\
\hline
\end{tabular}

Data analysis revealed four potentially significant quantitative indicators of a "phantom" developing. First, we saw increases in signal-to-noise ratio (SNR) (a measure of strength of contraction, defined as the sum of myoelectric energy on all channels on the residual limb for 0.15 seconds after motion start divided by the sum of myoelectric energy on all channels on the 
From "MEC '08 Measuring Success in Upper Limb Prosthetics," Proceedings of the 2008 MyoElectric Controls/Powered Prosthetics Symposium, held in Fredericton, New Brunswick, Canada, August 13-15, 2008.

residual limb for 0.15 seconds prior to motion start). On average, SNR improved $250 \%$ from the pre-phantom to the post-phantom data subsets. Two subjects ended the data session with steadily increasing SNRs. Figure 1 shows SNR versus motion trial for subject 9, who became aware of a phantom at motion trial 260. SNR slope versus time averaged negative for the five traumatic amputees, as muscle fatigue resulted in weaker contractions over time. SNR slope for our subjects with congenital limb deficiencies averaged positive in spite of fatigue.

\section{Figure 1}

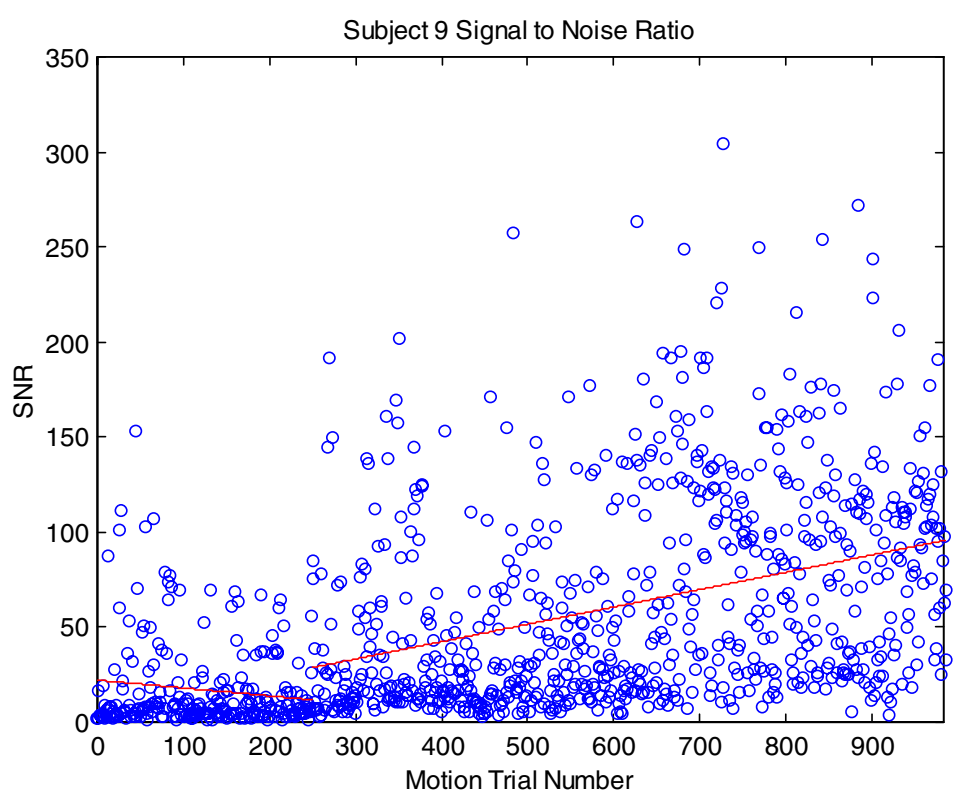

Second, the delay between the motion prompt and myoelectric response in the residual limb decreased after the phantom sensation began. Figure 2 shows the motion start delays for Subject 9. The post-phantom consistency is striking compared to the earlier scatter. Third, motion errors (where the subject told us that they made the wrong response to the motion cue) decreased after the phantom perception. Table 3 shows the error rates for the three subjects who had a distinct onset of the phantom

sensation. Pre-phantom error rates for these three subjects averaged $4.4 \%$ versus $1.7 \%$ postphantom [3].

\section{Figure 2}

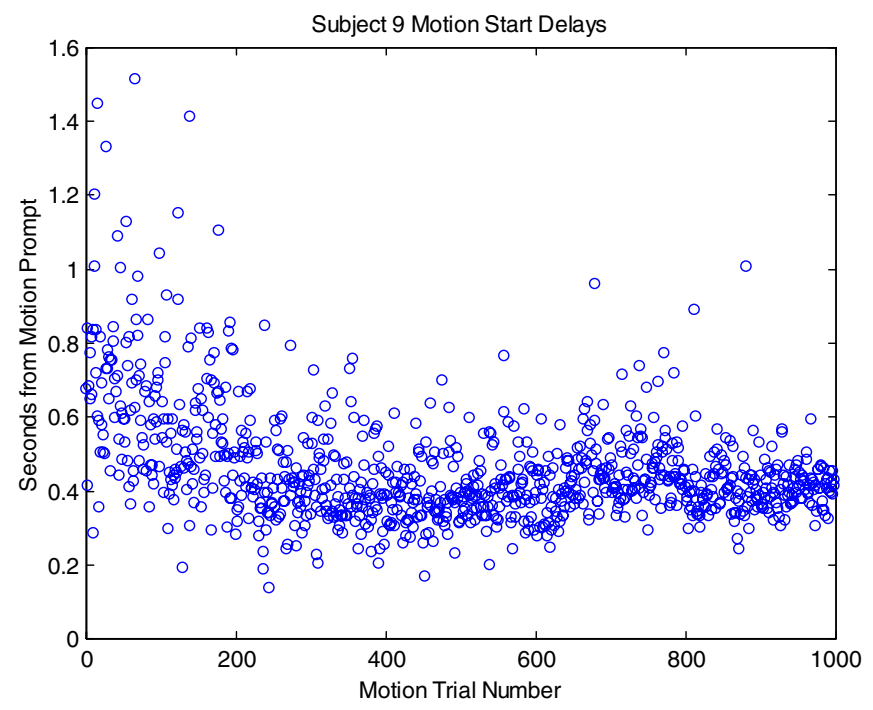

Fourth, we saw increases in motion identification accuracy of a simulated prosthesis controller [4] after the "phantom" appeared. For two of the subjects (8 and 9) who had distinct onsets of the perception of the missing hand, we compared a genetic-programming prosthesis controller based on (1) the entire data set and (2) the data collected after the subject perceived the "phantom." Evolutionary computing techniques such as genetic programming generally produce better results with larger training

data sets, so we expected the accuracy for subjects 8 and 9 to be lower for the more restricted training data sets, all else being equal. Instead, the prosthesis controller motion identification 
From "MEC '08 Measuring Success in Upper Limb Prosthetics," Proceedings of the 2008 MyoElectric Controls/Powered Prosthetics Symposium, held in Fredericton, New Brunswick, Canada, August 13-15, 2008.

accuracy increased 3.1\% for subject 8 and $4.2 \%$ for subject 9 . Thus, the contractions recorded in the residual limb were more motion-specific after the subject began feeling the missing hand.

\begin{tabular}{|c|c|c|c|}
\hline Subject & Total Error Rate & $\begin{array}{l}\text { Pre-Phantom Error } \\
\text { Rate }\end{array}$ & $\begin{array}{l}\text { Post-Phantom Error } \\
\text { Rate }\end{array}$ \\
\hline 8 & $2.9 \%$ & $5.0 \%$ & $2.0 \%$ \\
\hline 9 & $1.8 \%$ & $3.6 \%$ & $1.2 \%$ \\
\hline 10 & $2.9 \%$ & $4.5 \%$ & $1.9 \%$ \\
\hline Average & $2.5 \%$ & $4.4 \%$ & $1.7 \%$ \\
\hline
\end{tabular}

\section{DISCUSSION AND CONCLUSIONS}

Is this sensation our congenital volunteers reported truly a phantom limb? Or just very active imagination and increasing proficiency in mental visualization with practice? The myoelectric data suggest that muscles were coordinating in more distinct motion-specific patterns after the phantom sensation began.

The congenitally limb-deficient subjects reported that they felt that both the visible hand and the phantom were moving identically, although perhaps a little slower. The only exception to this was some difficulty in completely closing or straightening the phantom fingers reported by two subjects. The limits to mobility of the hand perceptions - the difficulty in completely closing or opening the fingers - reported by these two volunteers is a particularly compelling qualitative argument that these sensations were a phantom, because three of our five traumatic amputees reported feeling this same limit in their phantoms' mobility.

These results were an unexpected product of a project focused on developing a prosthesis controller. They are preliminary and need validation in a study focused specifically on the development of phantom limbs among congenitally limb-deficient persons.

\section{Acknowledgements}

Thanks to T. Walley Williams III, Volunteer Test Subjects, Robert Abramcyzck, Mara Novy, Diane Atkins, Dr. William Donovan, Jeffrey Graham, J. Jaime Fernandez, NASA/JSC, and The Institute for Rehabilitation and Research (TIRR).

\section{Funding}

(1) Cooperative Research Agreement between the National Aeronautics and Space Administration's Johnson Space Center (NASA/JSC) and The Institute for Rehabilitation and Research (TIRR) at the Texas Medical Center; (2) , and US Department of Education Small Business Innovative Research (SBIR) ED-98-P0-4645; and (3) National Institutes of Health (NIH) SBIR 1 R43 HD36928-01..

\section{REFERENCES}

1. Farry, K.A., Fernandez, J.J., Abramczyk, R., Novy, M., and Atkins, D., “Applying Genetic Programming to Control of an Artificial Arm,” MEC'97, Fredericton, New Brunswick, Canada, July 23-25, pp. 50-55, 1997.

2. Farry, K.A., Fernandez, J.J., Graham, J.S., "User-Adaptive Myoelectric Control of Multifunction Prostheses,” Progress Report, NIH SBIR 1 R43 HD36928-01, 2000.

3. Farry, K.A., Fernandez, J.J., Graham, J.S., “An Artificial Hand Controller to Assist Children with Amputations in School and Play,” Final Report, ED-98-PO-4645, 1999.

4. Farry, K.A., Fernandez, J.J., Graham, J.S., "Method of Evolving Classifier Programs for Signal Processing and Control,” U.S. Patent No. 6,272,479. 